\title{
SECURITY BASED HOME SURVEILLANCE SYSTEM USING ANDROID APPLICATION
}

\author{
Madhavi Shinde ${ }^{1}$, Rutuja Shinde ${ }^{2}$, Neelam Thavare ${ }^{3}$, Amol Baviskar $^{4}$ \\ ${ }^{1}$ Student, Computer Department, JSPM's BSIOTR (W), Maharashtra, India \\ ${ }^{2}$ Student, Computer Department, JSPM's BSIOTR (W), Maharashtra, India \\ ${ }^{3}$ Student, Computer Department, JSPM's BSIOTR (W), Maharashtra, India \\ ${ }^{4}$ Professor, Computer Department, JSPM's BSIOTR $(W)$, Maharashtra, India
}

\begin{abstract}
This paper proposes a classic approach to provide security aspects for a home based system. The mobile robot is controlled from a distance by a human operator through a GUI(Graphical User Interface). In this, it includes the simulation of the sensors to predict the actions of the robot. In this proposed project, we design a robot that will be used under Surveillance Vicinity. The robot and thus the surrounding area will be under surveillance. Any changes in the robot's movements can be viewed via the camera mounted on the robot/ceiling. Also, any intrusion attacks or occurrences will be received to the human operator through SMS Alerts or Internet Based Services on the Android phones. The GUI (Graphical User Interface) that is made in the software will receive the live images from the camera. The Android app that is created can control and view the robot and surrounding and obtain feedback of the same.
\end{abstract}

Keywords: Image Processing Techniques, Security and SMS Alerts.

\section{INTRODUCTION}

With the growing amount of technologies, there is more demand for security and safety. Thus, there is a need to develop one such entity to provide that. In this proposed paper, we design a mobile robot using the fundamentals of Image Processing. The mobile robot refers to a moving robot which is designed to work in the video surveillance areas.

We have made use of Temperature sensor, IR sensors and Gas sensor for the Home surveillance system. The IR sensors are placed on the windows for detecting the intrusion. On intrusion, the buzzer is activated and SMS is sent to the user via Internet based services.

\subsection{Objectives}

The objectives are as follows-

1. Enhance security aspects for home environment [1]: Security aspects are the main focus of the project. In the home environment, it becomes more important to provide security from thefts and other unusual problems. The system consists of static passwords for the home users to login. With this, it becomes possible to monitor the surrounding environment of the house, move the robot in the house, set up the alarm whenever intrusion occurs, when the gas leakage occurs and the signaling of temperature variation. Silent alarm and alarm signal detect the surrounding intrusions.

2. To improve Human-Robot interaction [2]: The basic aim is to develop and enhance the Human-Robot interaction. Robots can be of great use to humans. They can be regarded as fruitful substitutes to watchmen. In this way, they provide security from thefts, robberies and unusual occurrences at home too. This Human-Robot application is easy to build and deploy on any far machine too.

\section{IMPLEMENTATION AND WORKING}

The proposed paper shows the implementation for the project. It includes the basic principles of Image Processing and the use of Android Application. The designing section of the project includes the placing of sensors such as Temperature, Gas and IR. Camera can be either placed on the robot or the ceiling. The live video feedback is given to the user using the Android application. The user having the Android phone can use the server from a remote area through exchange of IP address. On detection of intrusion, the buzzer and alarm are signaled, hereby, indicating occurrence of a third person or any casualties like Gas leakage, Fire alarm, thefts etc. The occurrences of these events are sent to the user who is using the Android phone via SMS alerts. These SMS alerts are sent with the help of Internet Based Services. 


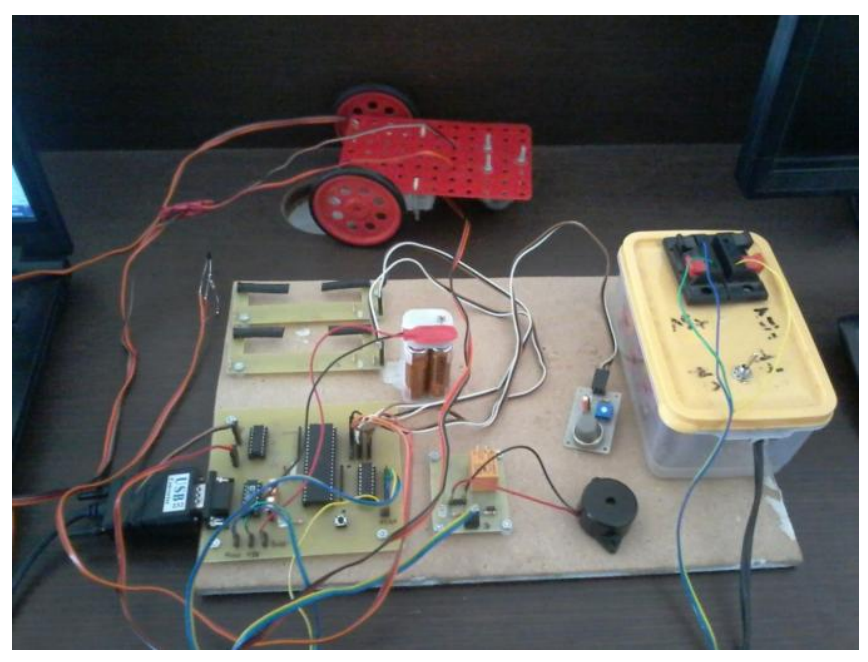

Fig -1: Hardware Implementation

The above Fig -1 shows the hardware implementation of the project. Hardware components are used for interfacing it with the Computer and other software components. Following are the components being used-

- $\quad$ Server Computer

- Client Phone

- ATMega32L

- L293D

- ULN2803

- $\quad$ Sensors(Temperature, GAS and IR)

- Robot

- Buzzer

- Drivers and serial Cable

\section{CONCLUSIONS}

The proposed paper aims at providing security for a home environment. It makes use of an Android application by using it on an Android phone. A moving robot is used to support this project .The project can be extended by using the robot on a multi-purpose basis. From the Client and Server modules, it is seen that the user can access from the client side as well as from the Sever side.

\section{ACKNOWLEDGEMENTS}

We would like to express our sincere gratefulness to our parents and all those people who have helped us directly or indirectly for the completion of this work.

\section{REFERENCES}

[1]. Neelam Thavare*, Madhavi Shinde, Rutuja Shinde, Prof. Amol Baviskar "Mobile Robot Movements Using Image Processing for Home Surveillance." Internationa Journal of Advanced Research in Computer Science and Software Engineering 3(11),November -2013, pp.1008-1010.
[2]. W. Burgard, A.B. Cremers, D. Fox, D. H"ahnel,G. Lakemeyer, D. Schulz, W.Steiner, and S.Thrun.Experiences with an interactive museum tour-guide robot. Artificial Intelligence, 114(1-2):3-55, 1999.

[3]. N. Roy and S. Thrun:"Online Self-Calibration For Mobile Robots", paper published in 1998.

[4]. Fleury, S. and Baron, T., 1992, "Absolute External Mobile Robot Localization Using a Single Image. Proceedings of the 1992 SPIE Conference on Mobile Robots, Boston, MA, Nov.18-20, pp. 131-143.

\section{BIOGRAPHIES}

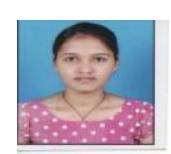

Madhavi Shinde, Student, JSPM BSIOTR(W)

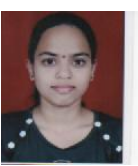

Rutuja Shinde, Student, JSPM BSIOTR(W)

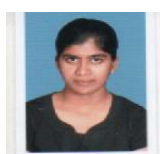

Neelam Thavare, Student, JSPM, BSIOTR(W)

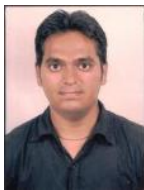

Prof. Amol Baviskar, Professor, JSPM $\operatorname{BSIOTR}(\mathrm{W})$ 